\title{
Adenoviral-mediated transfer of vascular endothelial growth factor 121 cDNA enhances myocardial perfusion and exercise performance in the nonischemic state
}

\author{
Paul Schalch, MD \\ G. Farah Rahman, $M D^{\mathrm{a}}$ \\ Gerald Patejunas, $\mathrm{PhD}^{\mathrm{a}}$ \\ Robert A. Goldschmidt, MD \\ JoAnn Carbray, BS ${ }^{\mathrm{a}}$ \\ Mauricio A. Retuerto, BS ${ }^{a}$ \\ David Kim, BS ${ }^{\mathrm{a}}$ \\ Karyn Esser, $\mathrm{PhD}^{\mathrm{d}}$ \\ Ronald G. Crystal, MD ${ }^{\mathrm{c}}$ \\ Todd K. Rosengart, MDa,b
}

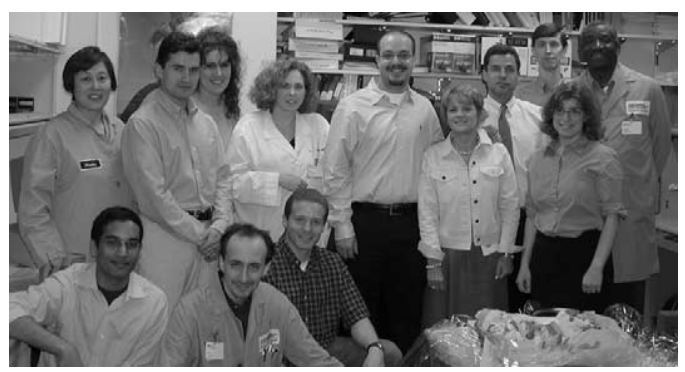

Background: Angiogenic gene therapy has been demonstrated to enhance perfusion to ischemic tissues, but it is unknown whether the administration of angiogenic growth factors will increase blood flow to nonischemic tissues. This study investigates whether enhanced myocardial perfusion can be mediated by adenovirus-mediated transfer of vascular endothelial growth factor 121 cDNA to nonischemic myocardium.

Methods: New Zealand White rabbits received adenovirus $\left(5 \times 10^{10}\right.$ particle units) encoding for vascular endothelial growth factor $121(\mathrm{n}=$ 14) or a control vector without a transgene $(n=13)$ or saline solution ( $n$ =9) via direct myocardial injection. Fluorescent microsphere perfusion studies and histologic analyses were performed 4 weeks later. In a parallel study, exercise treadmill testing was performed to assess the functional effects of this therapy in Sprague-Dawley rats.

From Evanston Northwestern Healthcare, ${ }^{\mathrm{a}}$ Evanston, Ill; Northwestern University Medical School, ${ }^{\mathrm{b}}$ Chicago, Ill; Weill Medical College of Cornell University, ${ }^{\mathrm{c}}$ New York, NY; and University of Illinois at Chicago, ${ }^{\text {d }}$ Chicago, Ill.

Supported, in part, by the National Institutes of Health/National Heart, Lung, and Blood Institute (R01HL57318 and R01HL61719), Evanston Northwestern Healthcare Women's Auxiliary Fund (Evanston, Ill), and Gen Vec, Inc (Rockville, Md).

Received for publication Dec 9, 2002; revisions requested April 21, 2003; accepted for publication June 5, 2003.

Address for reprints: Todd K. Rosengart, MD, 2650 Ridge Ave, Burch 100, Evanston, IL 60201 (E-mail: trosengart@enh. org).

J Thorac Cardiovasc Surg 2004;127:535-40 $0022-5223 / \$ 30.00$

Copyright ( $\odot 2004$ by The American Association for Thoracic Surgery

doi:10.1016/j.jtcvs.2003.06.015
Results: Microsphere assessment of myocardial perfusion in rabbits 4 weeks after adenovirus-encoding vascular endothelial growth factor administration was greater than that for rats injected with control vector without a transgene or saline solution ( $3.2 \pm 0.5$ vs $2.7 \pm 0.7$ and $2.4 \pm 0.4$, respectively; $P<.03$ ). The endothelial cell count per high power field was increased in animals injected with adenovirusencoding vascular endothelial growth factor versus animals injected with control vector without a transgene or saline solution $(147 \pm 27$ vs $123 \pm 14$ and $125 \pm 16$ cells, respectively), although this did not reach statistical significance $(P=.12)$. Rats treated with adenovirus-encoding vascular endothelial growth factor also demonstrated prolonged exercise tolerance compared with rats injected with control vector without a transgene or saline solution (exhaustion time: $26 \pm 5$ minutes vs $19 \pm 2$ minutes and $20 \pm 3$ minutes, respectively; $P=.006$ ).

Conclusions: Adenovirus encoding-mediated transfer of vascular endothelial growth factor 121 induces an enhancement in regional perfusion in nonischemic myocardium that corresponds to changes in exercise tolerance. Adenovirus-encoding vascular endothelial growth factor therapy may be useful for inducing angiogenesis in the nonischemic state, such as for prophylactic therapy of early coronary artery disease. 


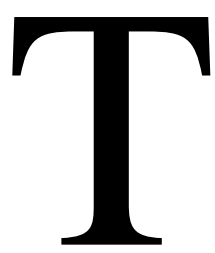

he administration of growth factors has been demonstrated to enhance blood vessel growth and perfusion to ischemic tissues in a number of models. ${ }^{1-5}$ It has been postulated that such "therapeutic angiogenesis" will not occur in nonischemic tissues because of an absence of adequate growth factor receptor up-regulation in these tissues. ${ }^{6-9}$ This hypothesis has in part served as the rationale for systemic delivery of angiogenic agents, assuming that potentially deleterious angiogenesis will not occur in "normal" tissues but only in ischemic tissues possessing an appropriate level of receptor up-regulation. ${ }^{7-9}$

Contrary to these suppositions, growth factor administration has been demonstrated to enhance tissue vascularization in several nonischemic models. ${ }^{10-15}$ Growth factors have also been successfully administered as a prophylactic therapy prior to vascular ligation. ${ }^{13-15}$ It is likely that this observed induction of angiogenesis in nonischemic tissues is made possible in part by the ability of growth factors to up-regulate the expression of their own receptor; for example, as in the case of vascular endothelial growth factor (VEGF) up-regulation of flk-1. ${ }^{16}$

It has not been previously determined whether the administration of angiogenic growth factors will cause a physiologically significant increase in perfusion to nonischemic tissues, as opposed to only increasing blood vessel number. Theoretically, such enhanced perfusion might result in improved functional capabilities of these tissues. Importantly, such findings would refute the existing presumption that up-regulation of receptor expression in ischemic tissues will limit angiogenic effects to these tissues following systemic growth factor administration. This study consequently investigates the effects of adenoviral-mediated transfer of VEGF121 cDNA to nonischemic myocardium and demonstrates enhanced myocardial perfusion and improved exercise tolerance in this setting.

\section{Materials and Methods \\ Ad Vectors}

The replication-defective vector AdVEGF is an E1a ${ }^{-}$, partial $\mathrm{E}^{-} \mathrm{b}^{-}$, partial E3 ${ }^{-}$adenovirus (Ad) vector based on human Ad serotype 5, with the expression cassette inserted in the E1 region in the right-to-left orientation. The expression cassette includes the cytomegalovirus immediate early promoter/enhancer, an artificial splice sequence, the human VEGF121 cDNA, and the simian virus 40 poly(A)/stop signal. ${ }^{17}$ As a negative control, a similar adenovirus (AdNull) containing no gene in the expression cassette was used. All Ad vectors were propagated, purified, and quantitated as previously described, and all replication-defective vector preparations were demonstrated to be free of replication-competent adenovirus. ${ }^{17}$ VEGF protein expression by AdVEGF was confirmed by enzyme-linked immunosorbent assay (R\&D Systems, Minneapolis, Minn), with $\sim 500 \mathrm{ng}$ VEGF detected per $1 \times 10^{11}$ particle units (pu) of AdVEGF assayed in culture.

\section{Perfusion Studies (Rabbit)}

Male New Zealand White rabbits (average weight $3 \mathrm{~kg}$; Covance Research Products, Denver, Pa) were treated in accordance with institutional animal care and use committee (IACUC) guidelines. The rabbits were sedated with subcutaneous ketamine $(35 \mathrm{mg} / \mathrm{kg})$ and xylazine $(2 \mathrm{mg} / \mathrm{kg})$. Following endotracheal intubation, general anesthesia was maintained with $3 \mathrm{~L} \mathrm{O}_{2}$ and intravenous fentanyl $(150 \mu \mathrm{g} / \mathrm{kg})$. A left lateral thoracotomy was then performed, and $5 \times 10^{10} \mathrm{pu}$ of AdVEGF $(\mathrm{n}=14)$, AdNull $(\mathrm{n}=13)$, or saline solution $(n=9)$ was delivered via direct myocardial injection using a $27 \mathrm{G}$ tuberculin syringe at 4 sites on the anterior and posterior left ventricular walls at the midventricular level (25 $\mu \mathrm{L}$ per injection), encompassing the left ventricular free wall.

Four weeks later, a repeat thoracotomy was performed and $2 \times$ $10^{6}$ fluorescent $15-\mu \mathrm{m}$ microspheres (Molecular Probes, Eugene, Ore) were injected via left atrial cannulation. After killing the animals under general endotracheal anesthesia, the left ventricle was sectioned into upper, middle, and apical thirds. The upper and middle sections (rings) were divided into septal, anterior, and posterior segments, while the apical section was preserved as 1 segment. Spheres were liberated from these segments by alkali digestion and quantified in a blinded fashion, as previously described. ${ }^{18}$ An index of perfusion was calculated as the ratio of the microspheres per gram of tissue extracted from each ventricular segment divided by the number of microspheres per gram of tissue extracted from the (untreated) upper septum, which served as an internal reference. A composite upper and lower ventricular perfusion index was calculated as the sum of the perfusion indices of the treated upper and middle rings, respectively.

\section{Histologic Evaluation (Rabbit)}

Three additional groups of rabbits underwent the administration of AdVEGF $(n=9)$, AdNull $(n=8)$, or saline solution $(n=7)$ as described above. Four weeks later, the animals were killed after a pentobarbital overdose $(150 \mathrm{mg} / \mathrm{kg} \mathrm{IV})$, the hearts were prepared for histologic analysis in $10 \%$ neutral buffered formalin, embedded in paraffin, and sectioned. Endothelial cells were stained for 1 hour with a 1:100 dilution of biotinylated Griffonia simplicifolia lectin (Vector Labs, Burlingame, Calif). Stained regions were visualized using an avidin-biotin-peroxidase complex and diaminobenzidine substrate, as previously described. The mean endothelial cell count was calculated in a blinded fashion from the number of endothelial cells seen in 3 randomly selected high-power fields from these sections of the injected regions of the left ventricle and the (uninjected) upper and lower septum.

\section{Exercise Protocol (Rat)}

Male Sprague-Dawley rats (average weight 360 g; Harlan, Indianapolis, Ind) were treated in accordance with IACUC guidelines. Rats were administered five injections $(20 \mu \mathrm{L})$ of AdVEGF or AdNull $\left(1 \times 10^{10} \mathrm{pu}\right)$ or saline solution $(\mathrm{n}=8$ per group) in a manner analogous to that for the rabbit studies. Prior to injection, all animals were trained for 10 minutes on a multitrack small animal motorized treadmill (Model 42-15, Quinton, Bothell, Wash) at a constant speed of $15 \mathrm{~m} / \mathrm{min}$. Two weeks after surgery, the rats were exercised on the same treadmill according to a standardized protocol, as follows: $10 \mathrm{~m} / \mathrm{min}$ for 5 minutes, 15 $\mathrm{m} / \mathrm{min}$ for 5 minutes, and $25 \mathrm{~m} / \mathrm{min}$ for the remainder of the 


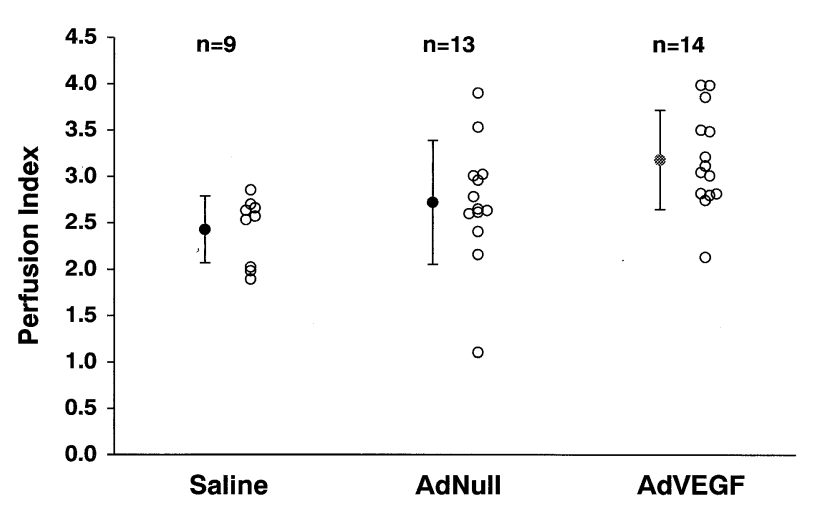

Figure 1. Microsphere perfusion to the lower ventricle of rabbits 4 weeks following treatment. Results for each animal and mean \pm standard deviation are shown.

experiment. ${ }^{19}$ Exhaustion was defined as the time point at which the animals rats sustained 10 falls per minute onto the electrified grid at the end of each running track. ${ }^{19}$

\section{Statistical Analysis}

Data are expressed as means and standard deviations. Analysis of variance with Bonferroni correction was used to show significance for all analyses.

\section{Results}

\section{Rabbit Myocardial Perfusion}

A composite myocardial perfusion index was calculated from microsphere harvests from nonischemic rabbits 4 weeks following the administration of AdVEGF, AdNull, or saline solution (Figure 1). The composite index for the lower ventricle was significantly greater $(P<.03) 4$ weeks after AdVEGF administration (3.2 \pm 0.5$)$ compared with the composite index 4 weeks after the administration of AdNull $(2.7 \pm 0.7)$ or saline solution $(2.4 \pm 0.4)$. In comparison, perfusion to the upper ventricular segments was not significantly different between groups $(P>.6)$, consistent with the pattern of injections and the cephalad to caudad course of coronary flow.

A trend toward enhanced perfusion to the noninjected lower septum was also demonstrated in animals treated with AdVEGF versus animals treated with AdNull or saline solution (lower septum perfusion index: AdVEGF, $0.94 \pm$ 0.17; AdNull, $0.81 \pm 0.22$; saline solution, $0.79 \pm 0.14$; $P=.095)$. Increased perfusion of the septum through perforating branches of the left anterior descending coronary artery, which courses through the area of injection, may in part explain this finding.

\section{Rabbit Myocardial Histology}

Mean endothelial cell number per microscopic field in the injected anterior and posterior midventricular segments was increased in animals injected with AdVEGF versus AdNull
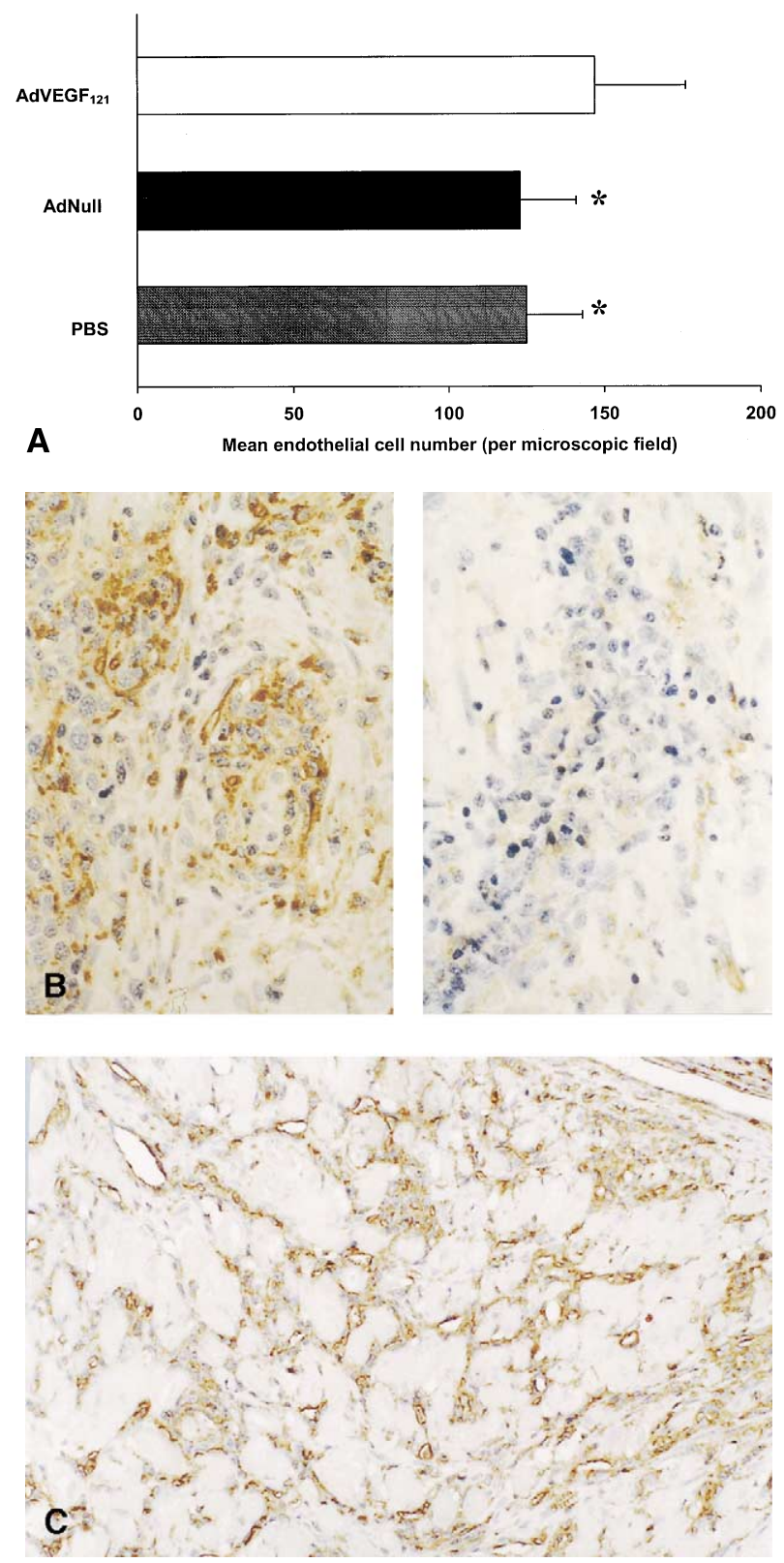

Figure 2. Histologic assessment of rabbit myocardium following treatment. A, Quantification of endothelial cell number per high power field in treatment groups, as indicated (mean \pm standard deviation). ${ }^{*} P=.12$. B, Left panel: Lectin stain of a VEGF injection site shows endothelial cells in brown $(400 \times)$; right panel: lectin stain of a control heart (injected with saline solution) shows almost no endothelial cell staining $(400 \times)$. C, Lectin stain of a VEGF-injected heart adjacent to injection site shows vascular channels infiltrating the myocardium $(200 \times)$.

or saline solution $(147 \pm 27$ vs $123 \pm 14$ and $125 \pm 16$ cells, respectively), although this did not reach statistical significance $(P=.12$; Figure $2, A)$. Consistent with the expectation of localized spread of the Ad vector beyond the 


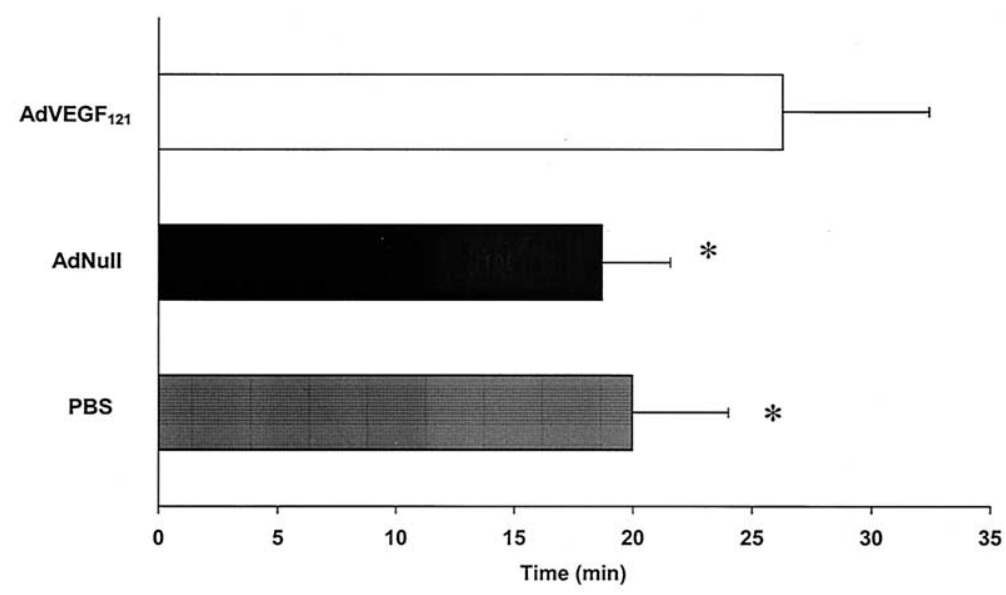

Figure 3. Time to exhaustion (mean \pm standard deviation) for rat treadmill testing 2 weeks following various treatment regimens, as described in Methods. ${ }^{*} P<.006$.

area immediately surrounding the injection site, endothelial cell number in the noninjected lower septum also demonstrated a trend toward increased values in animals injected with AdVEGF versus AdNull or saline solution (156 \pm 28 vs $112 \pm 26$ and $114 \pm 18$ cells, respectively; $P=.13$ ). Qualitative analysis of treated territories is remarkable for the lack of inflammation or infarction noted in these tissues (Figure 2, B, C). Histologic analysis in AdVEGF-treated animals furthermore suggests a predominant pattern of small-vessel development.

\section{Rat Exercise Tolerance}

AdVEGF-treated rats demonstrated significantly prolonged exercise tolerance $(P=.006) 2$ weeks postinjection (average time to exhaustion: $26 \pm 5$ minutes) compared with animals treated with AdNull (19 \pm 2 minutes) or saline solution (20 \pm 3 minutes; Figure 3).

\section{Discussion}

The present study demonstrates an increase in perfusion in nonischemic myocardial tissue and an improvement in exercise tolerance following the administration of vascular endothelial growth factor by means of an adenovirus vector. These findings are consistent with the ability of VEGF and other growth factors to mediate the up-regulation of their own receptors, ${ }^{16}$ although these studies do not prove a causal relationship in this regard. Importantly, these data refute the existing assumption that potentially deleterious angiogenesis will not occur in sensitive tissues such as the retina or in occult tumors in the absence of ischemic upregulation of angiogenic receptors, an assumption which has served as the rationale for systemic administration of angiogenic growth factors in some clinical trials. ${ }^{7-9}$

Although it cannot be ruled out that some degree of ischemia induced by surgical manipulation or other stresses did not play a role in enhancing perfusion in this study, the significantly greater changes in perfusion and exercise tolerance observed in the VEGF compared with the non-VEGF control groups suggest that this is not the case. Although it would be useful to determine whether substantial degrees of ischemia would have created an even greater enhancement of perfusion than that observed in this nonischemic model, the presence of different baseline levels of perfusion in ischemic versus nonischemic hearts unfortunately precludes a meaningful comparison of this parameter. Further, given the relatively high levels of perfusion in the nonischemic myocardium, it is not unexpected that the increases in perfusion noted in this study were only modest.

The observed increase in endothelial cell number in the present study, although not statistically significant, is consistent with improvements seen in previously reported results for nonischemic tissues. ${ }^{1,13,14}$ It is difficult to account for the relative discrepancy between the modest increase in endothelial cell number and relatively greater increases in physiologic parameters noted in these and other studies in ischemic models. ${ }^{1-6}$ Conceivably, these differences may be related in some way to the artifact of the "two-dimensionality" of histologic analyses (ie, many cells out of the microscopic plane are not visualized) and the potentially nonlinear relationship between new vasculature and the perfusion and enhancement of function potentially provided by these vessels.

It is interesting to note that endothelial cell number and perfusion to the ventricular septum were increased in the present study, despite the limiting of injections to the left ventricular free wall. This finding is consistent with a pattern of global improvement in ventricular function we have noted following direct myocardial injection of AdVEGF to the left ventricular free wall in a pacing model of cardio- 
myopathy ${ }^{20}$ and our prior observations of only partial localization of transgene expression following intramyocardial delivery. ${ }^{21-23}$ Localized angiogenic effects in treated areas may result in enhanced perfusion to neighboring territories through collateral flow, such as the septal branches of the left anterior descending, which in turn is situated in a treated myocardial territory. Alternatively, the septal tissue may be exposed to AdVEGF through the local diffusion of the aqueous vector solution through the myocardium or through transmyocardial vascular transport.

Data in the present study suggest but do not prove the likelihood of long-term persistence of the noted perfusion changes, nor do they prove a prophylactic capability for this therapy in preventing or minimizing myocardial infarction in the setting of a subsequent vascular occlusion. Given the fact that adenoviral-mediated VEGF expression is largely extinguished by 1 week after vector administration, ${ }^{12,21-23}$ however, the presence of increased perfusion at 4 weeks after vector administration suggests that these changes persist at least beyond the duration of VEGF expression. Our prior observations of neovasculature persistence at 90 days following AdVEGF administration in the rat fat pad and findings of a prophylactic effect in peripheral and myocardial ischemia models after vector administration ${ }^{12-15}$ similarly suggest that persistence of perfusion changes is possible, as do our recent findings in a prophylactic peripheral model 6 weeks after vector administration (unpublished data). It has been suggested that the administration of angiogenic cofactors such as angiopoietin-1 or platelet-derived growth factor might further stabilize and allow the persistence of a neovasculature. ${ }^{24,25}$ Alternatively, the presence of flow through newly created vessels might create sufficient impetus for persistence without such additional therapy. The findings of this study suggest that angiogenic therapy may be of benefit in treating tissues not traditionally considered to be ischemic, such as those neighboring an ischemic myocardial segment in patients with coronary artery disease, or in nonatherosclerotic conditions, such as ventricular hypertrophy or enlargement in the setting of valvular disease. These findings also suggest the possibility of creating tissues that may function in "hypernormal" modes; for example, when accelerated wound healing is required. Finally, given evidence of correlations between treadmill aerobic running capacity and left ventricular function in isolated heart preparations, ${ }^{26,27}$ the enhancement of exercise tolerance noted in the AdVEGF-treated "normal" animals may indicate that myocardial perfusion may be a limiting component in cardiac performance. We are aware that such treatment holds implications for improving athletic performance.

We thank B. Cushing for help in preparation of this manuscript.

\section{References}

1. Harada K, Grossman W, Friedman M, Edelman ER, Prasad PV, Keighley CS, et al. Basic fibroblast growth factor improves myocardial function in chronically ischemic porcine hearts. J Clin Invest. 1994; 94:623-30.

2. Giordano FJ, Ping P, McKirnan MD, Nozaki S, DeMaria AN, Dillmann WH, et al. Intracoronary gene transfer of fibroblast growth factor-5 increases blood flow and contractile function in an ischemic region of the heart. Nat Med. 1996;2:534-9.

3. Mack CA, Patel SR, Schwarz EA, Zanzonico P, Hahn RT, Ilercil A, et al. Biologic bypass with the use of adenovirus-mediated gene transfer of the complementary deoxyribonucleic acid for vascular endothelial growth factor 121 improves myocardial perfusion and function in the ischemic porcine heart. J Thorac Cardiovasc Surg. 1998;115:168-76.

4. Pu LQ, Sniderman AD, Brassard R, Lachapelle KJ, Graham AM, Lisbona R, et al. Enhanced revascularization of the ischemic limb by angiogenic therapy. Circulation. 1993;88:208-15.

5. Ferrara N, Isner JM. Gene transfer of naked DNA encoding for three isoforms of vascular endothelial growth factor stimulates collateral development in vivo. Lab Invest. 1996;75:487-501.

6. Pu LQ, Sniderman AD, Arekat Z, Graham AM, Brassard R, Symes JF. Angiogenic growth factor and revascularization of the ischemic limb: evaluation in a rabbit model. J Surg Res. 1993;54:575-83.

7. Hendel RC, Henry TD, Rocha-Singh K, Isner JM, Kereiakes DJ, Giordano FJ, et al. Effect of intracoronary recombinant human vascular endothelial growth factor on myocardial perfusion: evidence for a dose-dependent effect. Circulation. 2000;101:118-21.

8. Epstein SE, Kornowski R, Fuchs S, Dvorak H. Angiogenesis therapy: amidst the hype, the neglected potential for serious side effects. Circulation. 2001;104:115-9.

9. Simons M, Annex RH, Laham RJ, Kleiman N, Henry T, Dauerman H, et al. Pharmacological treatment of coronary artery disease with recombinant fibroblast growth factor-2. Circulation. 2002;105:788-93.

10. Okamoto N, Tobe T, Hackett SF, Ozaki H, Vinores MA, LaRochelle $\mathrm{W}$, et al. Transgenic mice with increased expression of vascular endothelial growth factor in the retina: a new model of intraretinal and subretinal neovascularization. Am J Pathol. 1997;151:281-91.

11. Ferrara N, Davis-Smyth T. The biology of vascular endothelial growth factor. Endocr Rev. 1997;18:4-25.

12. Magovern CJ, Mack CA, Zhang J, Rosengart TK, Isom OW, Crystal RG. Regional angiogenesis induced in nonischemic tissue by an adenoviral vector expressing vascular endothelial growth factor. Hum Gene Ther. 1997;8:215-27.

13. Gowdak LH, Poliakova L, Wang X, Kovesdi I, Fishbein KW, Zacheo A, et al. Adenovirus-mediated VEGF(121) gene transfer stimulates angiogenesis in normoperfused skeletal muscle and preserves tissue perfusion after induction of ischemia. Circulation. 2000;102:565-71.

14. Safi J Jr, DiPaula AF Jr, Riccioni T, Kajstura J, Ambrosio G, Becker LC, et al. Adenovirus-mediated acidic fibroblast growth factor gene transfer induces angiogenesis in the nonischemic rabbit heart. Microvasc Res. 1999;58:238-49.

15. Mack CA, Magovern CJ, Budenbender KT, Patel SR, Schwarz EA, Zanzonico $\mathrm{P}$, et al. Salvage angiogenesis induced by adenovirusmediated gene transfer of vascular endothelial growth factor protects against ischemic vascular occlusion. J Vasc Surg. 1998;27:699-709.

16. Kremer C, Breier G, Risau W, Plate KH. Up-regulation of flk-1/ vascular endothelial growth factor receptor 2 by its ligand in a cerebral slice culture system. Cancer Res. 1997;57:3852-9.

17. Rosenfeld MA, Yoshimura K, Trapnell BC, Yoneyama K, Rosenthal ER, Dalemans W, et al. In vivo transfer of the human cystic fibrosis transmembrane conductance regulator gene to the airway epithelium. Cell. 1992;68:143-55.

18. Glenny RW, Bernard S, Brinkley M. Validation of fluorescent-labeled microspheres for measurement of regional organ perfusion. $J$ Appl Physiol. 1993;74:2585-97.

19. Laughlin MH, Simpson T, Sexton WL, Brown OR, Smith JK, Korthius RJ. Skeletal muscle oxidative capacity, antioxidant enzymes, and exercise training. J Appl Physiol. 1990;68:2337-43.

20. Leotta E, Patejunas G, Murphy G, Szokol J, McGregor L, Carbray J, et al. Gene therapy with adenovirus-mediated myocardial transfer of vascular endothelial growth factor 121 improves cardiac performance 
in a pacing model of congestive heart failure. $J$ Thorac Cardiovasc Surg. 2002;123:1101-13.

21. Lee LY, Patel SR, Hackett NR, Mack CA, Polce DR, El-Sawy T, et al. Focal angiogen therapy using intramyocardial delivery of an adenovirus vector coding for vascular endothelial growth factor121. Ann Thorac Surg. 2000;69:14-24.

22. Magovern CJ, Mack CA, Zhang J, Hahn RT, Ko W, Isom OW, et al. Direct in vivo gene transfer to canine myocardium using a replication-deficient adenovirus vector. Ann Thorac Surg. 1996;62: 425-33.

23. Lee LY, Zhou X, Polce DR, El-Sawy T, Patel SR, Thakker GD, et al. Exogenous control of cardiac gene therapy: evidence of regulated myocardial transgene expression after adenovirus transfer of expres- sion cassettes containing corticosteroid response element promoters. J Thorac Cardiovasc Surg. 1999;118:26-35.

24. Thurston G, Suri C, Smith K, McClain J, Sato TN, Yancopoulos GD, et al. Leakage-resistant blood vessels in mice transgenically overexpressing angiopoietin-1. Science. 1999;286:2511-4.

25. Hellstrom M, Gerhardt H, Kalen M, Li X, Eriksson U, Wolburg H, et al. Lack of pericytes leads to endothelial hyperplasia and abnormal vascular morphogenesis. J Cell Biol. 2001;153:543-53.

26. Seward SW, Seiler KS, Starnes JW. Intrinsic myocardial function and oxidative stress after exhaustive exercise. J Appl Physiol. 1995;79:251-5.

27. Barbato JC, Lee SJ, Koch LG, Cicila GT. Myocardial function in rat genetic models of low and high aerobic running capacity. Am J Physiol Regula Integr Comp Physiol. 2002;282:721-6. 